\title{
Evaluation and Modelling of Integral Capacitors Produced by Interdigitated Comb Electrodes
}

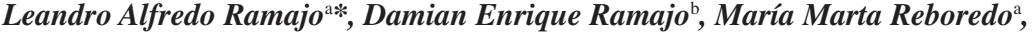 \\ Diego Hernan Santiago , Miriam Susana Castro $^{\mathrm{a}}$ \\ anstitute of Research in Material Science and Technology - INTEMA, \\ CONICET, University of Mar del Plata, \\ Juan B Justo 4302 (B7608FDQ), Mar del Plata, Argentina \\ ' International Center for Computational Methods in Engineering, CIMEC, INTEC, \\ Güemes 3450 (S3000GLN), Santa Fe, Argentina
}

Received: September 18, 2008; Revised: December 10, 2008

\begin{abstract}
Integral capacitors (IC) of one or two-layer printed wiring board (PWB) circuits were produced using comb electrodes fixtures and dielectric composites as the inter-electrode material. ICs were fabricated at laboratory scale, using copper comb electrodes and BaTiO3-epoxy composite materials deposited on a glass-Epoxy FR4 board. They were experimentally tested in order to obtain their electrical response. Furthermore, ICs behaviour was modelled through 2-dimensional models applying finite element method (FEM). Results showed that by this laboratory technique it was possible to obtained integral capacitors with low dielectric losses. Moreover, acceptable agreement was found between numerical and experimental capacitance results for all the different analysed ICs. In conclusion, 2D FEM models are a suitable tool to predict electric response of IC devices.
\end{abstract}

Keywords: integral capacitors, dielectric composites, FEM

\section{Introduction}

Interdigital capacitors (IDC) for technological applications have been studied by many authors since the early 1970s. The applications of these components include lumped elements for microwave integrated circuits ${ }^{1-3}$, optical and surface acoustic wave devices ${ }^{2}$, optically controlled microwave devices ${ }^{4}$, thin-film acoustic-electronic transducers and comb electrodes devices for dielectric characterization of polymers and ceramics materials ${ }^{5}$. Recently, IDC have been studied for humidity determinations ${ }^{6-7}$ and gas sensing ${ }^{8-10}$. Typical interdigital capacitive sensors (IDC-S) are made of an "inert" substrate over which comb electrodes are depositated. In this way, polymers, as active material, have been used for organic vapour sensing because they exhibit rapid reversible vapour absorption and are easy to apply as thin or thick films by a variety of techniques ${ }^{11}$. These sensor arrays can be part of an electronic nose for a particular application depending on the sensitive layers that are chosen.

Usually, integral capacitors (IC) are plane devices, based on the ground and power sheets of the printed wiring boards (PWB) to create the two conductors, applying then a dielectric material in order to separate them. Moreover, IC with one or two layers of PWB could be produced using comb electrodes in order to reduce costs and optimize the process design of new electronic circuits. Nevertheless, the main problem of these devices is the difficulty to obtain components with specific characteristics because of the absence of analytical expressions to predict their electrical response. If both combs have interdigitated electrodes with the same shape and an infinite top air layer, the structures can be acceptably approximated with the proposed method of capacitance computation ${ }^{11}$. Despite this, for electronic applications, the specific capacitances need to be known for every different configuration. In this way, finite element method (FEM) can be used in order to determine the effective capacitance, modelling IC real geometries by means of 2D and 3D models.

On the other hand, polymeric composite materials, consisting of dielectric ceramic particles immersed in an epoxy resin, have been reported to have interesting properties for a wide range of applications ${ }^{12-14}$, like passive electronic devices. Because of their good performance and low cost, small size and light weight, polymeric ceramic materials have arisen much attention mainly for microelectronic packaging applications.

In this work, ICs made by using comb electrodes and a dielectric polymeric composite material $\left(\mathrm{BaTiO}_{3}\right.$-epoxy) were fabricated and experimentally and numerically studied. The electric response of the composite material deposited on comb electrodes was evaluated by means of a quasistatic approximation using the constitutive Laplace equation. 2D periodic models were employed to represent the real geometry of IC, and FEM was applied in order to solve them. The numerical results were confronted with experimental ones measured at room temperature and at range of frequency from $20 \mathrm{~Hz}$ to $1 \mathrm{MHz}$.

\section{Experimental Procedure}

\subsection{Comb electrode geometry}

Due to photoengraving is widely used in the manufacture of PWB, comb electrodes were made by this technique, which allows to obtain wirings with definition of $250 \mu \mathrm{m}$. However, with our available laboratory technique, it is hardly to produce comb with wirings gaps smaller than $400 \mu \mathrm{m}$, so in this work ICs were fabricated using electrode-gaps of $400 \mu \mathrm{m}$ and $500 \mu \mathrm{m}$. Professional quality glassEpoxy FR-4 boards (with a copper sheet thickness of $35 \mu \mathrm{m}$ ) with blue coloured positive resin were used. A photomask and a glass substrate were deposited onto the boards, and then they were illuminated with UV light $(400 \mathrm{~nm})$, as depicted in Figure 1a. Later, the photoresist film was removed by applying a developer $\left(7\right.$ g.L $\mathrm{L}^{-1}$ sodium hydroxide in water) at room temperature during 2 minutes. Finally, boards were immersed in an acid bath of ferric chloride solution (35-40p/p\%) at approximately $45^{\circ} \mathrm{C}$ for 3 minutes. In all cases, ICs with an area of 
$1 \mathrm{~cm}^{2}$, a substrate permittivity of $5.8 \varepsilon 0$ (glass-Epoxy FR4 board) and electrode height of $25 \mu \mathrm{m}$ were prepared.

\subsection{Dielectric material}

Barium titanate ceramic powder $\mathrm{BaTiO}_{3}$ (TAM Ceramics Inc) was doped with 0.6 wt. (\%) of $\mathrm{Nb}_{2} \mathrm{O}_{5}$ to modify its dielectrical properties. Powders were immersed in isopropilic alcohol and mixed by agitation at $6000 \mathrm{rpm}$ during 5 minutes. Afterwards, the alcohol was eliminated by heating at $65^{\circ} \mathrm{C}$ until constant weight was reached. The powder was thermally treated at $1350^{\circ} \mathrm{C}$ for 180 minutes and cooled until room temperature was reached with a cooling rate of $3{ }^{\circ} \mathrm{C} / \mathrm{min}$. The powder was milled for 90 minutes in isopropilic alcohol using a planetary mill with $\mathrm{ZrO}_{2}$ balls (Fritsch, Pulverisette 7) until an average particle size of $1.4 \mu \mathrm{m}$ was obtained.

As regards the dielectric composite material, the matrix was made by mixing epoxy DER 325 (Dow Chemical), and DEH 324 (Dow Chemical) as the curing agent (12.5 phr), while the doped $\mathrm{BaTiO}_{3}$ was introduced as the discrete phase. The viscosity of the mixture was reduced by adding tetrahydrofuran (THF, Dorwil Chemical) at a concentration of $10 \mathrm{wt}$. (\%).

The ceramic powder was added to the epoxy resin at different volume fractions ( 0 to $40 \mathrm{vol}$. (\%)) and suitably blended by employing an ultrasonic mixer (Sonic vibra-cell $150 \mathrm{~W}$ ) during 4 minutes. Then, the different composites were deposited by pouring the material onto the glass-Epoxy FR- 4 boards and cured at $100^{\circ} \mathrm{C}$ for 2 hours. Finally, vacuum was applied in order to extract the THF.

The $\mathrm{BaTiO}_{3}$ concentration of the composites was analysed by thermal gravimetric technique (TGA, Shimadzu TGA-50) under controlled nitrogen atmosphere, starting from room temperature with a heating rate of $10^{\circ} \mathrm{C} / \mathrm{min}$ up to $800^{\circ} \mathrm{C}$. In addition, after the curing process the dispersion of $\mathrm{BaTiO}_{3}$ particles into the composites was analysed through Scanning Electron Microscope (SEM, JEOL 6460LV).

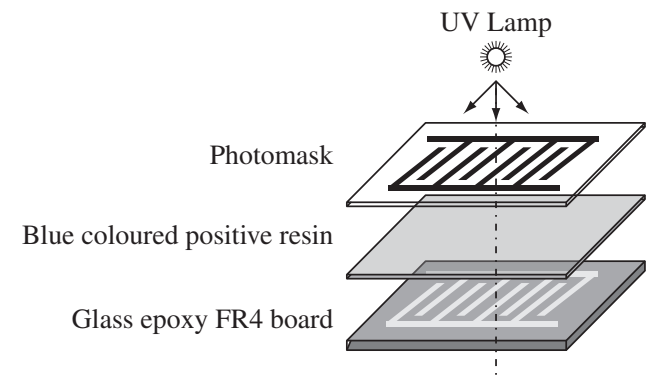

(a)

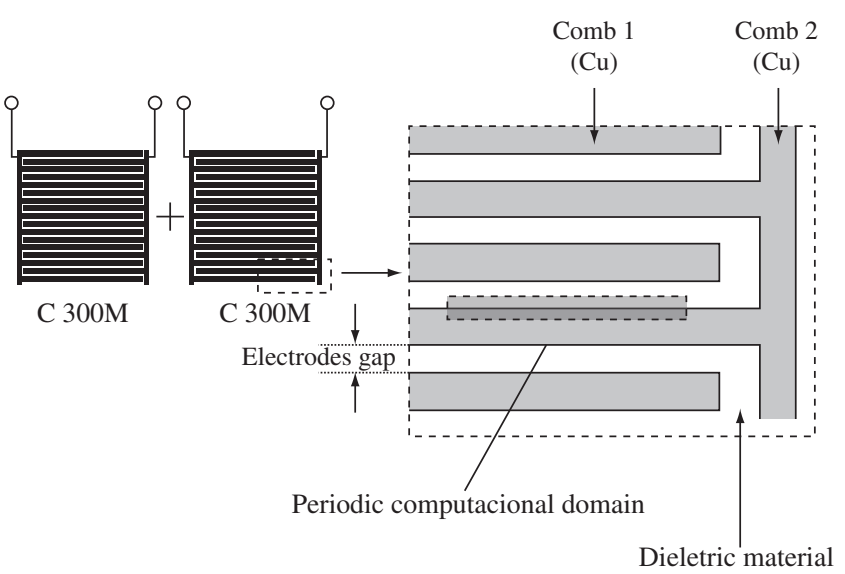

(b)

Figure 1. Outline and method of manufacture of comb electrode capacitors.
Electric measurements were performed at room temperature using a Hewlett Packard 4284A impedance analyzer in the frequency range from $20 \mathrm{~Hz}$ to $1 \mathrm{MHz}$. IC microstructure was studied using a scanning electron microscopy (SEM, JEOL 6460LV).

\section{Numerical Modelling}

Finite element analysis, using Petrov Galerking Standar, was applied to estimate the electrostatic potential distribution within the dielectric material and the effective capacitance of the combelectrodes configurations. More details about FEM formulation can be found in previous works ${ }^{12-13}$.

The capacitance $(\mathrm{C})$ of each electrode along the direction which corresponds to the applied electric field (V) was calculated by means of the following relationship ${ }^{14}$ :

$$
\begin{gathered}
\quad \mathrm{C}=\frac{\mathrm{q}}{\mathrm{V}}=\frac{\mathrm{C}_{(\mathrm{C} 1+\mathrm{C} 2)} \cdot \mathrm{C}_{(\mathrm{C} 1+\mathrm{C} 2)}}{2 \mathrm{C}_{(\mathrm{C} 1+\mathrm{C} 2)}}=\frac{\mathrm{C}_{(\mathrm{C} 1+\mathrm{C} 2)}}{2} \text {, being } \\
q=\varepsilon_{2} \oint E \cdot d A+\varepsilon_{1} \oint E \cdot d A
\end{gathered}
$$

where $q$ is the effective electric charge of electrodes, $E$ is the electric field, $\varepsilon_{1}$ and $\varepsilon_{2}$ are the permittivities of each surface and $A$ is the area of the surface where the field is applied.

Figure $1 \mathrm{~b}$ shows the computational domain extracted from the overall IC. As noted from this figure, a periodic assumption can be employed to represent the comb electrodes structures. So, to reduce the computational cost of simulations, only a small fraction of the overall geometry was considered (pointed as periodic computational domain in Figure 1b). Taking into account the two relevant parameters, the capacitance per unit of area was obtained.

The applied boundary conditions for $\mathrm{A}$ and $\mathrm{C}$ surfaces (see Figure 2) were a difference in potential $\left(\Delta \mathrm{V}=\mathrm{U}_{2}-\mathrm{U}_{1}\right)$ of $1 \mathrm{~V}$ along the $\mathrm{x}$ direction, a gradient of potential null in $\mathrm{x}$ direction $\left(\partial \mathrm{u} / \partial \mathrm{n}_{\mathrm{x}}=0\right)$, and finally a gradient of potential null along the $y$ direction at the other boundaries (B and D). Table 1 shows the initial and final volume fractions of $\mathrm{BaTiO}_{3}$ in the composites, and Table 2 displays the electric properties of the ICs tested. The permittivities reported in Table 2 were employed for computational simulations. Calculations were performed using a software developed by the authors and post processing of results was carried out with Octave.

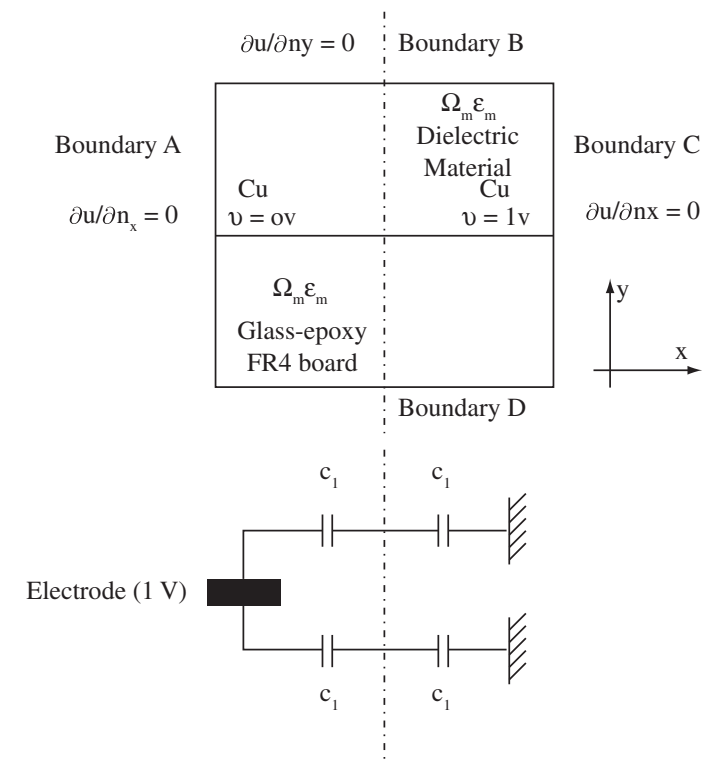

Figure 2. Boundary conditions applied over the computational domain. 


\section{Results and Discussion}

\subsection{Comb electrodes}

The measured $\mathrm{BaTiO}_{3}$ volume fractions and the corresponding solvent percentages retained inside the composites with different filler amount are shown in Table 1. A slight variation between initial and final $\mathrm{BaTiO}_{3}$ volume fraction and a low concentration of THF retained (below 1 wt. (\%)) after the curing step can be observed. These results suggest that there are not significant differences between initial and final $\mathrm{BaTiO}_{3}$ concentrations, and that the influence of solvent concentration can be negligible for numerical analysis.

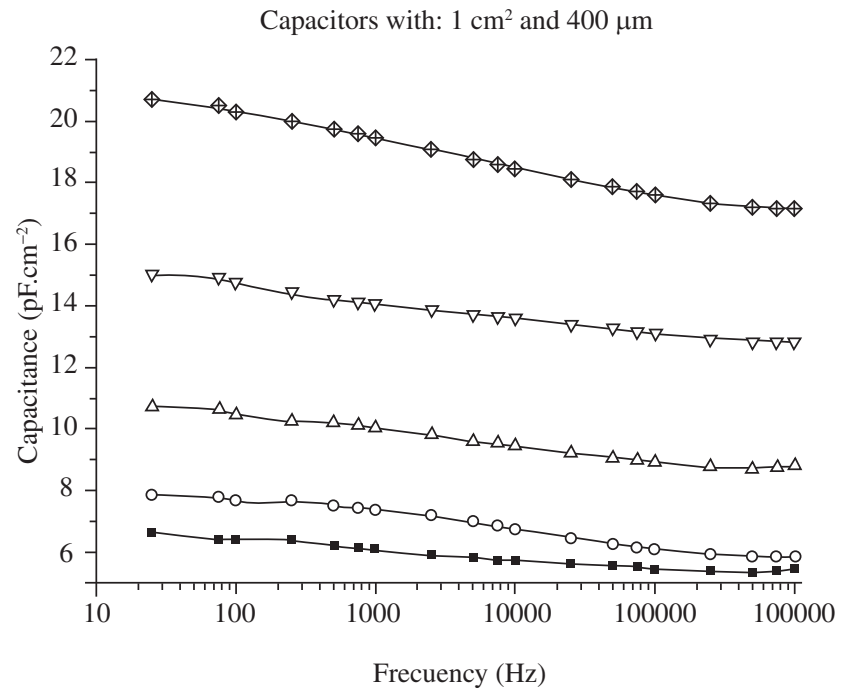

(a)

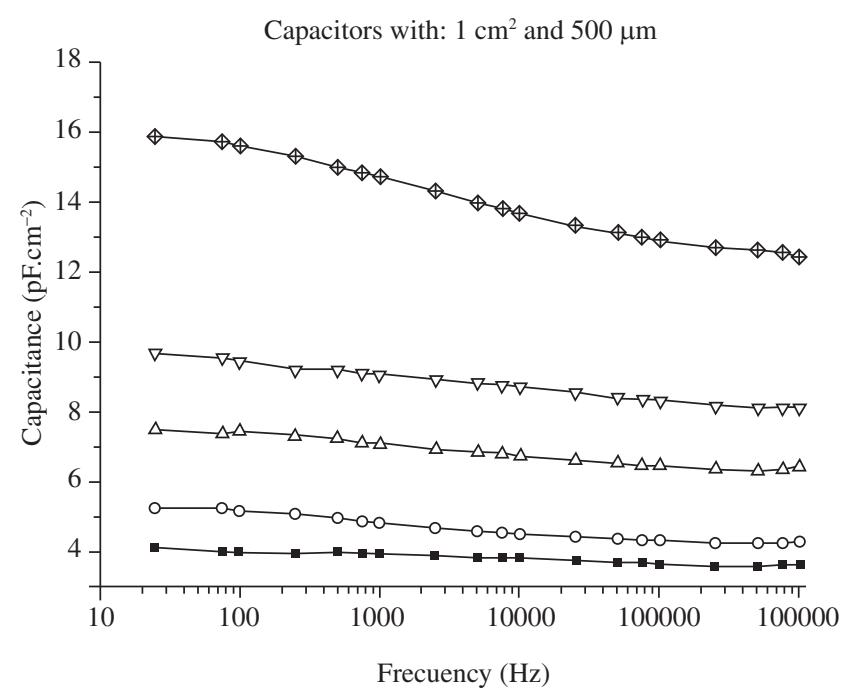

(b)

\begin{tabular}{lll}
$\longrightarrow \mathrm{BaTiO}_{3} 0 \%$ vol & $\longrightarrow$ & $\mathrm{BaTiO}_{3} 10 \%$ vol \\
$\longrightarrow \mathrm{BaTiO}_{3} 30 \%$ vol & $\smile \mathrm{BaTiO}_{3} 40 \%$ vol \\
$\square \mathrm{BaTiO}_{3} 20 \%$ vol & & \\
\hline
\end{tabular}

Figure 3. Experimental results of capacitance of interdigital capacitors with gaps between electrodes of 400 and $500 \mu \mathrm{m}$ as a function of frequency and $\mathrm{BaTiO}_{3}$ volume fraction at $20^{\circ} \mathrm{C}$.
The permittivity of composites and the capacitance of ICs for two electrodes gaps (400 and $500 \mu \mathrm{m})$ are shown in Table 2. It can be seen that capacitance increases as electrodes gap reduces. Moreover, capacitance is linearly proportional to permittivity and electrodes gap. So, IC capacitance of samples performed without any inter-electrode dielectric material (defined as Air in Table 2) represents the lowest capacitance value of each electrode gap analysed.

The capacitance and the loss tangent for both electrodes gaps as a function of frequency and filler amount are plotted in Figures 3 and 4, respectively. As expected, capacitance was influenced by frequency and filler concentration, and the slight decrease with frequency was due to the classic Debye process.

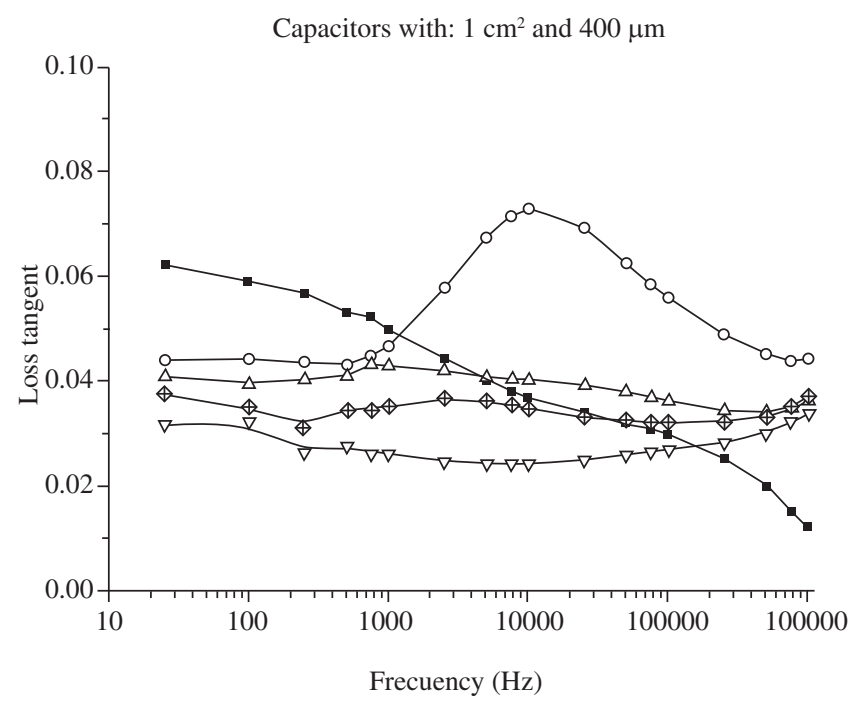

(a)

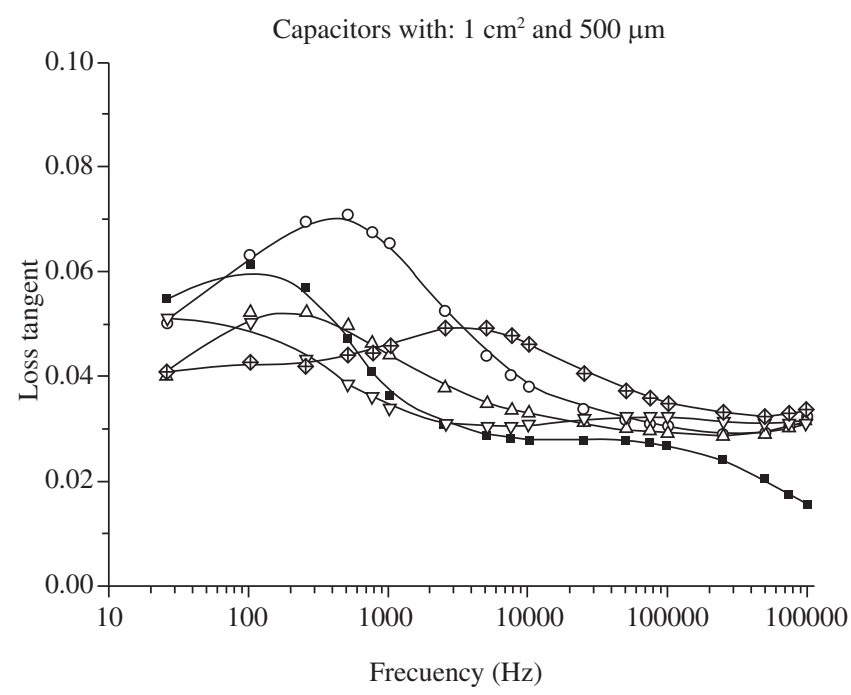

(b)

$\begin{array}{llll}\longrightarrow \mathrm{BaTiO}_{3} 0 \% \text { vol } & \longrightarrow & \mathrm{BaTiO}_{3} 10 \% \text { vol } \\ \longrightarrow \mathrm{BaTiO}_{3} 30 \% \text { vol } & \smile \mathrm{BaTiO}_{3} 40 \% \text { vol } \\ \square-\mathrm{BaTiO}_{3} 20 \% \text { vol } & & \end{array}$

Figure 4. Loss tangent of interdigital capacitors with gaps between electrodes of 400 and $500 \mu \mathrm{m}$ as a function of frequency and $\mathrm{BaTiO}_{3}$ volume fraction at $20{ }^{\circ} \mathrm{C}$. 
On the other hand, although, the system with 10 vol. (\%) of $\mathrm{BaTiO}_{3}$ and electrodes gap of $400 \mu \mathrm{m}$ showed an abrupt peak after $10 \mathrm{KHz}$, loss tangent did not show strong variations in the frequency range from $100 \mathrm{~Hz}$ to $10 \mathrm{KHz}$, In addition, the systems with electrodes gap of $500 \mu \mathrm{m}$ showed peaks for different frequencies. These peaks could be caused by a combination of several factors; the most important being the influence of the electrodes at low frequencies, the polarization effects, the influence of the substrate (at low filler concentration) and the high conductivity of the samples ${ }^{15}$.

Figure 5 shows SEM micrographs from transversal cross sections of samples with electrodes gaps of $400 \mu \mathrm{m}$ and different filler

Table 1. Initial and finally obtained volume fractions of $\mathrm{BaTiO}_{3}$ and retained THF percentages for composites with different filler concentrations (determined through $\left.{ }^{\mathrm{x}} \mathrm{TGA} ;{ }^{\S} \mathrm{DSC}\right)$. THF initial $=10 \mathrm{wt} .(\%)$.

\begin{tabular}{ccc}
\hline $\begin{array}{c}\text { Initial } \mathrm{BaTiO}_{3} \\
(\text { vol. }(\%))\end{array}$ & $\begin{array}{c}\text { Real } \mathrm{BaTiO}_{3}{ }^{\mathrm{x}} \\
(\text { vol. }(\%)\end{array}$ & $\begin{array}{c}\text { Retained THF } \\
(\text { wt. }(\%))\end{array}$ \\
\hline 10 & 10 & \\
20 & 19 & $<1 \%$ \\
30 & 28 & \\
40 & 39 & \\
\hline
\end{tabular}

Table 2. Permittivity of composites and capacitance of IC for two electrode gaps.

\begin{tabular}{lrrrrr}
\hline \multicolumn{1}{c}{ Material } & & Permittivity & \multicolumn{2}{c}{ Capacitance $\left(\mathrm{pF} / \mathrm{cm}^{2}\right)$} \\
& & \multicolumn{1}{c}{$\left(\varepsilon^{\prime}\right)$} & \multicolumn{1}{c}{$500 \mu \mathrm{m}$} & & \multicolumn{1}{c}{$400 \mu \mathrm{m}$} \\
\hline Air & & 1.00 & $2.81 \pm 0.22$ & & $3.89 \pm 0.16$ \\
Epoxi & & 4.12 & $4.02 \pm 0.21$ & & $5.83 \pm 0.37$ \\
Initial BaTiO & 10 & 7.00 & $5.10 \pm 0.12$ & & $7.79 \pm 0.32$ \\
(vol. (\%)) & 20 & 10.50 & $7.04 \pm 0.20$ & & $10.05 \pm 0.54$ \\
& 30 & 16.00 & $9.47 \pm 0.33$ & & $13.25 \pm 0.57$ \\
& 40 & 26.20 & $14.04 \pm 0.19$ & & $19.17 \pm 0.59$ \\
\hline
\end{tabular}

concentrations. Pictures show a good distribution of particles in all cases and small defects in samples with higher filler amount. In these specimens, the defects were generated during sample preparation for SEM analysis, due to the low flexibility of composites caused for the presence of ceramic inclusions.

Finally, defects on copper electrodes appeared as a result of the comb manufacturing process (etching in ferric chloride acid). Due to the electrode geometry, those defects were concentrated mainly on vertices. Also, the average height of the electrodes could be determined from micrographs, being $25 \mu \mathrm{m}$ with a dispersion of $10 \%$.

\subsection{FEM Model}

Numerical and experimental results of capacitance as a function of the material permittivity and the electrode gaps are presented in Figure 6. The numerical model fit the experimental points for elec-

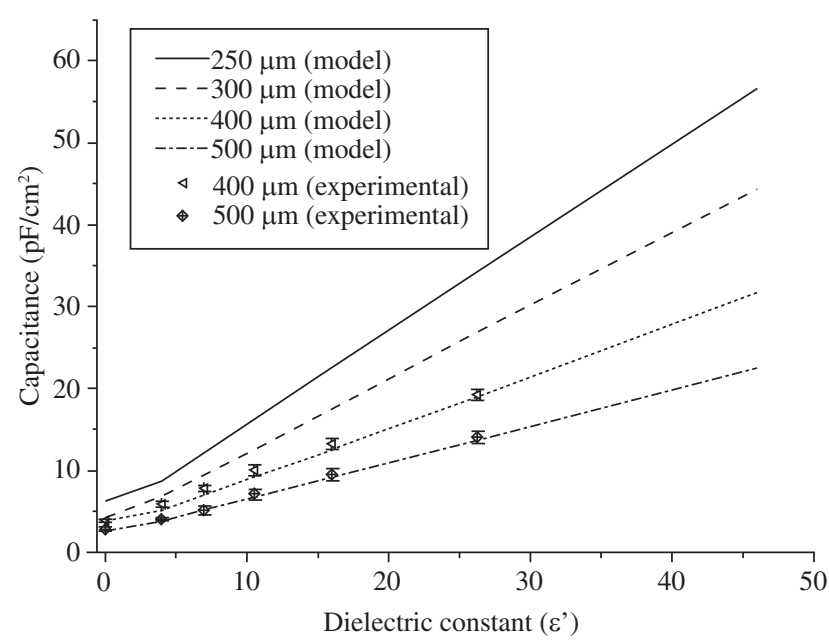

Figure 6. Numerical and experimental results as a function of the electrodes gaps and the dielectric constant for $20^{\circ} \mathrm{C}$ and $2500 \mathrm{~Hz}$.

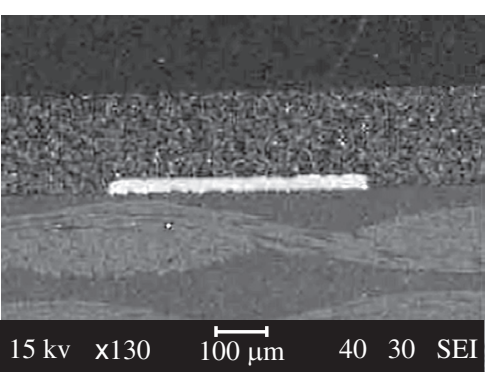

(a)

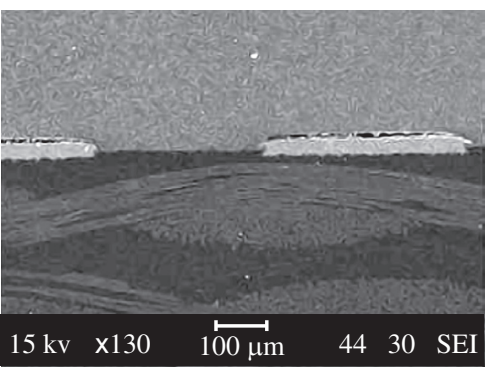

(d)

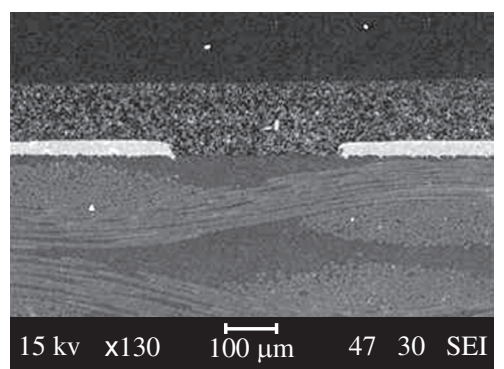

(b)

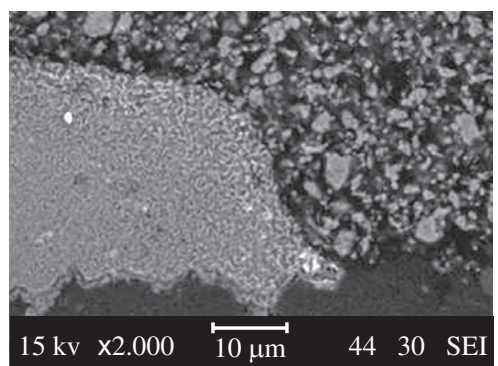

(e)

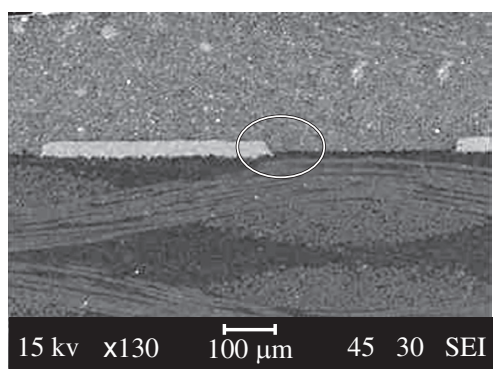

(c)

Figure 5. SEM of comb electrodes with: a) 10 vol. (\%), b), 20 vol. (\%), c) 30 vol. (\%), d) 40 vol. (\%) of BaTiO and e) amplification showing in detail the end of one electrode from picture c. 

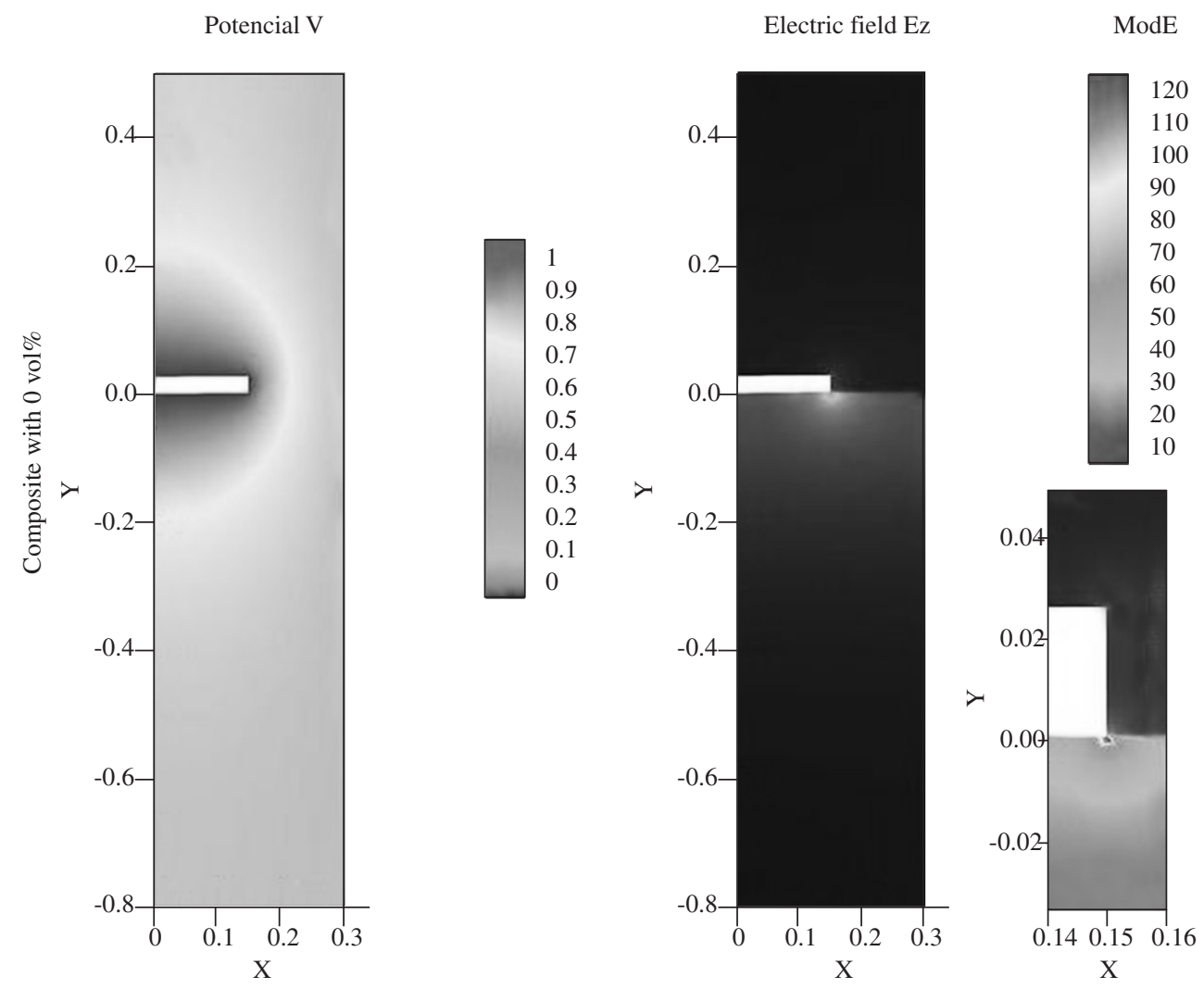

(a)
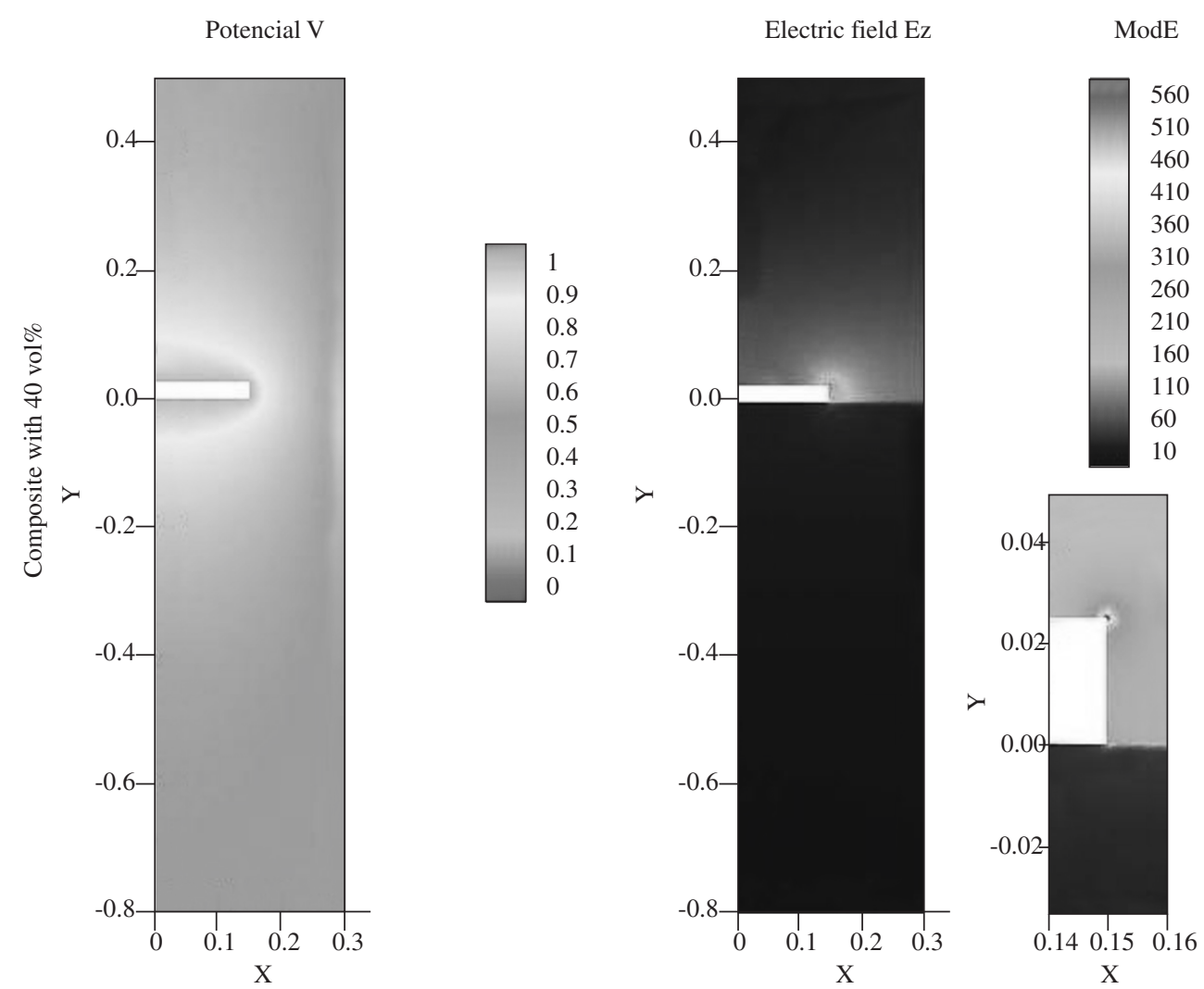

(b)

Figure 7. Potential and electric field intensities around an electrode for two IC with an electrodes gap of $300 \mu \mathrm{m}$ and filler fractions of 0 vol. (\%) (upper side) and 40 vol. (\%) (bottom side). 
trode gaps of 400 and $500 \mu \mathrm{m}$. It is easy to note the linear relationship between permittivity and capacitance which suggests that the substrate plays a very important role in composites with low dielectric permittivities, because the substrate permittivity represents the highest one of the system.

Results show that differences between FEM estimations and experimental data are lower than the experimental-error estimation. It allows to conclude that FEM is suitable to be used for predicting the capacitance of real IC as a function of the material dielectric constant for electrode gaps from 400 to $500 \mu \mathrm{m}$. As shown in Figure 6, if FEM predictions about IC with electrode gap of $250 \mu \mathrm{m}$ (maximum resolution of photogravure technique) are right, then capacitances upper than $50 \mathrm{pF} . \mathrm{cm}^{-2}$ could be obtained by using composite materials with dielectric constants of $55 \varepsilon_{0}$.

Figure 7 shows the numerical results of potential (V) and the electric field (Ez) for two IC with an electrode gap of $300 \mu \mathrm{m}$ and filler fractions of 0 and $40 \mathrm{vol}$. (\%). Note that the dielectric material thickness used to perform the capacitor is over dimensioned. So, it can be significantly reduced in order to decrease material costs. The potential distribution at both sides of the electrode is symmetric, while the electric field intensity is greatly increased in a small region near the electrode vertex. That is often attributed to field enhancement that occurs near the electrode tips ${ }^{15}$. In this sense, the material with the highest filler fraction (Figure 7 at the bottom) shows the highest electric field and the lowest potential spectra around the electrode.

\section{Conclusions}

A numerical and experimental research about the electrical response of comb-electrodes capacitors made of epoxy/BaTiO composites was carried out. Results of numerical simulations using FEM were confronted with experimental ones leading to the following conclusions:

- Experimental results showed that it is possible to manufacture integrated capacitors using comb electrodes. ICs have good frequency response and low loss, even though it is difficult to obtain relatively high capacitances;

- The composite material was distributed evenly on the capacitor surface, regardless of copper-electrodes surfaces showed an irregular shape due to chemical attack; and

- Experimental data were correctly fitted by means of 2D periodic FEM models, showing capability to predict the capacitance of IC with different electrodes gaps and inter-electrodes material properties.

\section{Acknowledgements}

This work was supported by National Council of Science and Technology of Argentina (CONICET). Also it was achieved thanks to collaboration of Eliseo Britos del Pino (CONICET's Technician).

\section{References}

1. Alley GD. Interdigital capacitors and their application to lumped-element microwave intergrated circuits. IEEE Transactions on Microwave Theory and Techniques. 1970; MTT-18: 1028-1033.

2. Wei JS. Distributed capacitance of planar electrodes in optic and accustic surface wave devices. IEEE Journal of Quantum Electronics. 1977; QE13 (4): 152-158.

3. Hoffman RK. Handbook of Microwave Integrated Circuits. Norwell MA: Artech; 1987.

4. Schaumburg G. Dielectrics Newsletter. Novocontrol Issue. Germany: Dirk Wilmer; 2006. p. 5-7.

5. Zaretsky MC, Mouayad L, Melchor JR. Continuum properties from interdigital electrode dielectrometry. IEEE Transactions on Electrical Insulation; 1988; 23(6): 897-917.

6. Qu W, Wlodarski W. A thin-film sensing element for ozone, humidity and temperature. Sensor and Actuators B, 2000; 64(1-3): 42-48.

7. Hagleitner C, Hierlemann A, Lange D, Kummer A, Kerness N, Brand O, Baltes H. Smart Single-Chip Gas Sensor Microsystem. Nature, 2001; 414(6861): 293-296.

8. Casalini R, Kilitziraki M, Wood D, Petty MC. Sensitivity of the electrical admittance of a polysiloxane film to organic vapours. Sensor and Actuators B. 1999; 56(1-2): 37-44.

9. Zhou R, Hierlemann A, Weimar U, Göpel W. Gravimetric, dielectric and calorimetric methods for the detection of organic solvent vapours using poly(ether urethane) coatings. Sensor and Actuators B. 1996; 34(1): 356-360.

10. Rui I, Dias CJ. Analytical evaluation of the interdigital electrodes capacitance for a multi-layered structure. Sensor and Actuators A. 2004; 112(2-3): 291-301.

11. Ramajo L, Reboredo MM, Castro MS. Dielectric response and relaxation phenomena in composites of epoxy with $\mathrm{BaTiO}_{3}$ particles. Composites Part A. 2005; 36(9): 1267-1274.

12. Ramajo L, Reboredo MM, Castro MS. Characterisation of epoxy/BaTiO composites processed by dipping for integral capacitor films (ICF). Journal of Materials Science, 2007; 42(10): 3685-3691.

13. Gregorio R, Cestari JM, Bernardino FE. Dielectric behaviour of thin films of b-PVDF/PZT and b-PVDF/BaTiO 3 composites. Journal of Materials Science. 1996; 31 (11): 2925-2930.

14. Beroual A, Brosseau C. Comparison of dielectric properties determined from a computational approach and experiment for anisotropic and periodic heterostructures. IEEE Transactions on Dielectrics and Electrical Insulation. 2001; 8(6): 921-929.

15. Deken B, Pekarek S, Dogan F. Minimization of Field Enhancement in Multilayer Capacitors. Computational Materials Science. 2006; 37(3): 401-409. 